\title{
Child-Pugh Class C14
}

National Cancer Institute

\section{Source}

National Cancer Institute. Child-Pugh Class C14. NCI Thesaurus. Code C146799.

A total score of 14 for hepatic function, corresponding to class C in the Child-Pugh classification. 